\title{
Bacterial Urinary Tract infection in adults, Hit District Anbar Governorate, west of Iraq.
}

\author{
Shehab A. Lafi ${ }^{1}$; Atheer Abdul-Hameed K. Alkarboly ${ }^{2}$ and \\ Mohamad S. Ahmed Lafi ${ }^{3}$ \\ 1- Medical Microbiology Department College of Medicine Anbar Uni. West of Iraq. \\ 2- College of Pharmacy Anbar Uni. West of Iraq. \\ 3- Medical Technologist, Anbar Health Deputy Affairs., Hit
}

\begin{abstract}
Background:

Urinary tract infection (UTI) is one of the health problems in the community in all ages and both sexes. Many organisms are involved particularly enteric bacteria in females. Antimicrobial resistance of bacterial pathogen are complaining treatment and recovery of infected individuals. So UTI become more complicated and recurrent trouble maker infection for community.
\end{abstract}

Aims of the study

This study was devoted to focus on the main bacterial pathogens causing UTI in adult patients from both sexes in Hit District as well as to show the Antibiogram of the predominant bacterial isolate from patients.

\section{Patients and methods}

Mid- stream urine specimens were collected from adult males and females, each specimen was cultivated on blood agar and Mac Conkey agar and incubated at 37C aerobically for 24 hours. Bacterial isolates were identified with Gram stain and biochemical tests. Predominant bacterial isolate, E. coli was tested for antimicrobial sensitivity test by disk diffusion test (Kerby-Bauer Technique).

\section{Results}

Adults females were showing higher rate of UTI than adult males $(77.8 \%)$, (263) and (59.6\%), (37) respectively. E. coli took first rank of isolation in both sexes, $26.5 \%$ in males and $40.8 \%$ in females. Staphylococcus became next (73), $(25.26 \%)$ while proteus mirabilis was showing third rank of isolation in both sexes. Regarding Antibiogram, E coli showed high sensitivity for imipenium (95.5\%) followed by Amikacin (90.2\%) while studied E coli isolate showed high tare of resistance to Ampicillin and Cotrimasol-Methprim.

\section{Conclusion:}

We can conclude from this study that UTI is an important infection in community and enteric bacteria particularly E. coli is an important causative agent. So precautions must be taken by people to prevent infection. Community education in self hygiene and social status must be done. Physicians must care of multi drug resistant E. coli during manipulation UTI

Keywords: UTI, Antibiogram, E. coli, Hit city

\section{INTRODUCTION}

Urinary tract infection (UTI) is defined as an inflammatory response of the urothelium to bacterial invasion (Stam and Norrby 2001 Tomas 2003).1

It occurs far more commonly in women than in men, except at the extremes of age, After 50 years of age, the incidence of UTI is almost as high in men as in women, presumably because of obstruction from prostatic hypertrophy. In persons between 1 and about 50 years of age, UTI is predominantly a disease of 
females. (Tomas, 2003, Kalpana and Walter, 2005).

Different classification was devoted for UTI to help treatment ,like upper and lower UTI, (Schaeffer, 2003). An increased rate of antimicrobial resistance was found to different antimicrobial agents due to abuse of antibiotics (Shafaq et al. 2011) and the emergence of resistance factors in bacteria trough different mechanisms of resistance $\left({ }^{6}\right.$ Nasreen et al. 2009 Shafaq et al. 2011).This study was done to show the rate of UTI and the type of bacteria imposed in this infection in adults in Hit District, West of Ramadi, Anbar Governorate, IRAQ

\section{Patients and methods:}

Midstream urine specimens were collected from (400) adult patients from both sexes using clean catch method recommended by (Vandepitte et al. 2003). Patients were attending private Clinics of Urologists and senior physicians in Hit District, Anbar Governorate, West of IRAQ.

Urine specimens were processed as soon as possible (within 30 minutes) in Hit Central Private Lab licensed by Iraqi Ministry of Health.

Urine samples were tested using direct and direct bacteriological investigations, direct smear stained with gram stain was employed to each specimen. Urine were cultivated on sterile culture media using blood agar and MacConkey agar and incubated aerobically under 37C for $24 \mathrm{hrs}$. Results of urine cultures were Interpretated quantitatively and qualitatively following (Vandepitte et al. 2003).

Bacterial isolates were identified and diagnosed using morphological and cultural criteria. Necessary confirmative tests were done to reach final diagnosis for each bacterial isolate following (Vandepitte et al. 2003, Forbes et al. 2011). Bacterial isolates were kept frozen in Brain Heart infusion broth containing $10 \%$ Glycerol.

Antimicrobial sensitivity test was done for the predominant bacterial isolate using Kirby-Bauer disc diffusion technique (Vandepitte et al. 2003). Standard E. coli strain employed as control, results were reported and analyzed using SPSS .

\section{RESULTS}

Adult females were showing higher rate of urinary tract infection than adult males, $263(77.8 \%)$ and 37 (59.6) respectively $(\mathrm{P}<0.05)$ Table1.

Table 1: Rate of UTI in both sexes

\begin{tabular}{|c|cc|cc|cc|}
\hline \multirow{2}{*}{ Sex } & \multicolumn{2}{|c|}{ Positive (+ve) } & \multicolumn{2}{c|}{ Negative (-ve) } & \multicolumn{2}{c|}{ Total } \\
& No. & $\%$ & No. & $\%$ & \multicolumn{2}{c|}{ No. } \\
\hline Male & 37 & 59.6 & 25 & 40.4 & 62 & 15.5 \\
\hline Female & 263 & 77.8 & 75 & 22.2 & 338 & 84.3 \\
\hline Total & 300 & 75 & 100 & 25 & 400 & 100 \\
\hline
\end{tabular}

E. coli took the first rank of isolation, 113 isolates with the ratio (39.1\% ) Out of 289 total $E$ coli isolates, $104(92.14 \%)$ were in females and the rest of isolates 9 (7.96) were in males.
Staphylococci became next to $E$ coli, 73, (25.2\%) and majority of them were coagulase negative staphylococci particularly Staphylococcus saprophyticus in females 47 , (16.2\%) (Table 2). 
Table 2: Bacterial types, single isolated.

\begin{tabular}{|c|c|c|c|c|c|c|}
\hline \multirow{2}{*}{ Bacterial isolate } & \multicolumn{2}{|c|}{ Male } & \multicolumn{2}{c|}{ Female } & \multicolumn{2}{c|}{ Total } \\
& \multicolumn{2}{|c|}{ No. $\%$} & \multicolumn{2}{c|}{ No. } & $\%$ & \multicolumn{2}{c|}{ No. } & $\%$ \\
\hline E.coli & 9 & 26.5 & 104 & 40.8 & 113 & 39.1 \\
\hline Klebsiella & 1 & 2.9 & 20 & 7.8 & 21 & 7.3 \\
\hline S.fecalis & 1 & 3.0 & 12 & 4.7 & 13 & 4.5 \\
\hline Proteous & 5 & 14.7 & 30 & 11.8 & 35 & 12.2 \\
\hline Pseudomonas & 2 & 5.9 & 10 & 3.9 & 12 & 4.1 \\
\hline Enterococcus & Zero & Zero & 1 & 0.4 & 1 & 0.3 \\
\hline Staf.aureus & 3 & 8.8 & 23 & 9.0 & 26 & 9.0 \\
\hline St.epidermes & 6 & 17.6 & 21 & 8.2 & 27 & 9.3 \\
\hline St.saproph. & 2 & 5.8 & 18 & 7.1 & 20 & 6.9 \\
\hline Actinobacter & Zero & Zero & Zero & Zero & Zero & Zero \\
\hline Enterobacter & 5 & 14.8 & 13 & 5.1 & 18 & 6.3 \\
\hline Salmonella & Zero & Zero & Zero & Zero & Zero & Zero \\
\hline Nisseria go. & zero & zero & Zero & Zero & Zero & Zero \\
\hline Candidia spp. & zero & zero & 3 & 1.2 & 3 & 1.0 \\
\hline Total & 34 & 11.7 & 255 & 88.3 & 289 & 100 \\
\hline
\end{tabular}

Proteus mirabilis was the third bacterium among isolated bacteria, 35 $(12.2 \%)$ and all bacterial isolates were showing higher rate of isolation in females than males $(\mathrm{P}<0.05)$ Table 2 .
Regarding mixed bacterial isolation, it was found that eleven (11) patients were showing positive urine cultures with mixed growth of more than one organism and majority of them were in females also (Table 3).

Table 3: Bacterial types, mixed isolates.

\begin{tabular}{|l|c|c|}
\hline \multicolumn{1}{|c|}{ Bacterial isolate } & $\begin{array}{c}\text { Male } \\
\text { NO. }\end{array}$ & $\begin{array}{c}\text { Female } \\
\text { NO. }\end{array}$ \\
\hline E.coli + Proteous & 1 & 1 \\
\hline E.coli + Pseudomonas & 1 & 1 \\
\hline Pseudomonas + Staf.aureus & 1 & Zero \\
\hline E.coli + St.epidermes & Zero & 1 \\
\hline Klebsiella + Staf.aureus & Zero & 1 \\
\hline Klebsiella + Proteous & Zero & 1 \\
\hline Pseudomonas + Proteous & Zero & 1 \\
\hline S.fecalis + Proteous & Zero & 1 \\
\hline E.coli +Enterobacter & Zero & 1 \\
\hline Total No.11 & 3 & 8 \\
Total \% 3.6 & 8.1 & 0.4 \\
\hline
\end{tabular}

The Antibiogram for the dominant isolated bacterial type (E. coli), it was found that $95.5 \%$ of $E$ coli isolates were sensitive to Imepimen and majority of them were from females (104) and the rest number (9) were from males. Amikacin became next (90.2 \%) followed by Ciprofloxacin. E coli isolates were showing high resistance to Ampicillin and Methiprim (Table 4).

Table 4: Antibiogram of E. coli isolated from UTI.

\begin{tabular}{|l|c|c|c|c|cc|}
\hline \multirow{2}{*}{ Antibiotics } & \multicolumn{2}{|c|}{ Female } & \multicolumn{2}{c|}{ Male } & \multicolumn{2}{c|}{$\begin{array}{c}\text { Total } \\
\text { Sensitive } \\
\text { No }\end{array}$} \\
\cline { 2 - 6 } & R No. & S No. & R No. & S No. & \multicolumn{1}{c|}{} \\
\hline Imipenium & 4 & 100 & 1 & 8 & 108 & 95.5 \\
\hline Amikacin & 9 & 95 & 2 & 7 & 102 & 90.2 \\
\hline Ciprofloxacin & 25 & 79 & 3 & 6 & 85 & 75.2 \\
\hline Nitrofuraltedon & 30 & 74 & 4 & 5 & 79 & 70 \\
\hline Refadin ${ }^{\circledR}$ & 55 & 49 & 7 & 2 & 46 & 40 \\
\hline Gentamicin & 51 & 53 & 5 & 4 & 57 & 50 \\
\hline Naladixic Acid & 39 & 65 & 6 & 3 & 65 & 57.5 \\
\hline Pencillin & 100 & 4 & 9 & 0 & 4 & 3.5 \\
\hline Methiprim & 96 & 8 & 9 & 0 & 8 & 7 \\
\hline
\end{tabular}




\section{DISCUSSION}

Increased rate of urinary tract infection (UTI) in females was in accordance with the findings of ( Nasreen et al. 2009., Manges, R.A et al. 2008, Khaled et al. 2010) The higher rate of urinary tract infection in females was ought to the feature of female urogenetal tract (short female urethra) which makes it easy to be contaminated with fecal flora $\left({ }^{11}\right.$ Naber 2000).

Aged males (particularly above 50 years old) tend to show an increased urinary tract infection (UTI), This was predisposed by the prostate infection and hypertrophy which leads to incomplete evacuation of urinary bladder due to urethral stenosis there leading to a residual volume of urine in the urinary bladder and this residual urine acts a good medium for bacterial growth in males ( Stamm and Hooton 1993, Kalpana et al. 2005). Enteric bacteria particularly E. coli showed the first rank of isolation in females and this was in accordance with the findings of ( Nasreen et al. 2009, Shafaq et al. 2011 ${ }^{9}$ Manges, R.A et al. 2008), this was due to the above mentioned explanation for the feature of female urogenetal tract exposed to sepses with fecal contents in which $E$. coli showed high count, $1 \times 10^{5}$ cell $/$ gr. Of stool (Brooks et al. 2007). E coli is an important pathogen in for the urinary tract, particularly uropathogenic strains through possessing adhesion pili and other adhessins that predispose bacterial binding to the uroethelium ( Jasmina et al. 2005, ${ }^{16}$ SOdernm 2011, Jacobson et al. 1985). In addition to that E. coli possess many other tools make it potent pathogen to urinary tract and other sites of the body (Jacobson et al. 1989 Brooks et al. 2007). So for the above mentioned criteria E. coli took the first rank of isolation from urinary tract infection in this study.

Staphylococcus, particularly Staphylococcus saprophyticus was showing a high rate of isolation in females and this was in agreement with the findings of (Anderson 2010, Wallmark et al. 1978, Roland A., 2002. This was attributed to the ability of Staphylococcus saprophyticus to reside urinary tract of virgin females and so imposed in the UTI among them (Mark et al. 1992, Brooks et al. 2007).
Staphylococcus aureus is an actual pathogen because it possesses virulence factors like protein A. and microcapsule in some strains which enable its binding on host tissue (Brook et al. 2007).

E. coli showed more mixed growth with other bacteria Staphylococcus species, this was due to the compatibility of such organisms to grow due to their physiological and growth features (Brook et al. 2007).

\section{Antibiogram of bacterial isolates:}

Regarding the Antibiogram results of E. coli studied isolates showed Imipenem, up on my knowledge this was ought to the reason that imipenem is newly used in Iraq as treating antibiotic so the local isolates still are not showing resistance to it, in addition to that imipenem is a carbapenem antibiotics which is highly active against Enteric bacteria producing ESBL( Ko et al. 2007). Our findings were in accordance with the findings of Nasreen et al. 2009 Shafaq et al. 2011).

Amikacin became next to imipenem, it showed high efficiency against $E$. coli isolates though it is available in Iraq before imipenem Many years ago, this was might be due to low resistance rate of bacterial isolates to Amikacin.

High rate of resistance of E. coli to cotrimasol- methprim and ampicillin in this study and this was in agreement with the findings of Shafaq et al. 2011, Nasreen et al. 2009) the ampicillin and Cotrimasolmethprim resistance is probably due to continuous use of it fro many years her, so the long exposure of bacteria to these antimicrobial agents trough use and the $E$. coli found the tool of resistance like beta lactame enzymes for ampicillin (Shafaq et al. 2011, Nasreen et al. 2009) who proved multidrug resistance plasmids for ESBL in E. coli. and folic acid alternatives for methiprim resistance (Brook et al. 2007) resistance Antimicrobial resistance was predisposed by increased exposure to antimicrobial agents through recurrence of infection and abuse and uncontrolled drug intake of patients through buying drugs without doctors prescription (self prescription). 
In the other hand majority of clinicians prescribe antibiotics without laboratory guidance (Wright et al. 2000).

We can conclude from this study that UTI is an important infection in community and enteric bacteria particularly E. coli is an important causative agent. So precautions must be taken by people to prevent infection. Community education in self hygiene and social status must be done. Majority of $E$. coli isolates were sensitive to imipenem and amikacin while they were showing high resistance to ampicillin and cotrimasol. So physicians must care of multi drug resistant E. coli during manipulation UTI, which showed the highest rate in UTI in HIT District .Restrictions must be taken against abuse of antibiotics trough buying drugs without doctor's prescription from pharmacy and following laboratory guidance during antibiotic therapy by physicians.

\section{REFERENCES}

Anderson, DJ.; Clark MA. and Anderson EM. (2010). Urinary tract infections due to Staphylococcus saprophyticus biotype 3. Can. Med. Assoc. J. 1981Feb.15; 124(4): 415-418.

Brooks, F. Geo; Carroll C. Karen; Butel S. Janet S. Morse A and Morse A. Stephen (2007). Jawetz, Melnick and Adelbergs Medical Microbiology, 24 ${ }^{\text {th }}$ ed. Mac Grow Hill publishers New York, USA

Forbes, A.B. Sahm, F. D. and Weissfeld S. Alice (2011). Bailey and Scotts diagnostic Microbiology, $12^{\text {th }}$ ed. Mosby Elsevier, China print.

Jacobson SH, Lins LE, Sevenso (1985). P fimbriated $\mathrm{E}$ coli : in adults with pyelonephritis . J. Infect. Dis., 152: 426427.

Jacobson SH.; Tullus K. and Brauner, A. (1989). Hydropic properties.

Jasmina, V.; Slavko SK. and Blazenka I. (2001). Low virulence of E. coli strains causing exacerbation of chronic pyelonephritis Acta. Clinic. Croat, 40:165-170.

Kalpana, G.; Walter, E. and Stamm, (2005). ACP Medicine section 7, XX11Urinary tract infection, a publication of American College of Physician.

Khalid M. Al-Dulaimi; Huda R. Al-Alwani and Fazea E. Al-Tarboli (2010). 2(1):
Ko, KS.; Suh JY. and Peck KR. (2007). In Vitro activity of fusomysin against ciprofloxacin resistant or Extended Blactamase Producing E. coli isolated from urine and blood. Diagn. Microbiol. Infect. Dis. 58:111-115.

Manges, AR.; Tabor, P. and Tellis C. (2008). Emerg. infec Dis. www.cdc.gov /EID.

Manges, AR.; Tobar, H. and Tellis, C. (2008). Emerg. Infect, Dis. http://www. Cdc.gov.com.

Mark E. Rupp; David E. Soper and Gordon L. Archer (1992). Colonization of the female genital tract with Staphylococcus saprophyticus, J. of Clinical Microbiol. Nov. pp.2975-2979.

Naber K.G. (2000). Treatment options for acute uncomplicated cystitis in adults, J. Antimicrob. Chemother., 46:23-27.

Nasreen, J.; Meshram, US. and Archana, K. (2009). Plasmid profile analysis of multidrug resistant E. coli isolated from patients of Nagpur city India. Romanian Biotechnological letters, 14(5): 46354640.

Roland A. (2002). The etiology of urinary tract infection: traditional and emerging pathogens Am. J. Med., 113(1):145-95.

Schaeffer, A J. (2003). Comments on UTI in :recent advances in treatment of UTI. Royal Society of Medicine Service, international Congress and Symposium Series, 97:721.

Shafaq Aiyaz Hassan, Syed Asfar Jamal and Mustafa Kamal (2011). Occurrence of multidrug resistant and ESBL producing $\mathrm{E}$ coli causing urinary tract infections, J. of Basic and Applied Sciences 7(1): 39-43.

Soderhall, M. (2001). The importance of E. coli fimbriae in UTI, Published and printed by Karolinska University Press, Stockholm, Sweden.

Stam W.E. (2001). and Norrby S.R. Urinary tract infections: disease panorama and challenges . J. Infect. Dis. 183 Suppl. 1: S1-S4.

Stamm, W. E. and Hooton, T. M. (1993). Management of urinary tract infections in adults. N. Eng. J. Med, 329: 1328-34

Tomas L. and Gribling MD. (2003). Urinary tract infection in women .J. Fam. Pract., 51:977.

Vandepetti, J.; Verhaegen, J. and Engbaek, K. (2003). Basic laboratory procedures 
in clinical bacteriology, Second ed. WHO Geneva Swiss.

Wallmark G. Arremark I. and Telander B. (1978). Staphylococcus saprophyticus a frequent cause of acute urinary tract infection among female outpatients. J. of Infect. Dis. 138:791-797.
Wright, S.; Wrenn, K. D.; Hyanes, M. and Hass, D.W. (2000). Prevalence and risk factors for multidrug resistant uropathogens in emergency patients. Am. J. Emerg. Med., 18: 143-146.

\section{ARABIC SUMMARY}

$$
\begin{aligned}
& \text { التهاب المجارى البولية في البالغين في مدينة هيت / محافظة الانبار / غرب العراق. }
\end{aligned}
$$

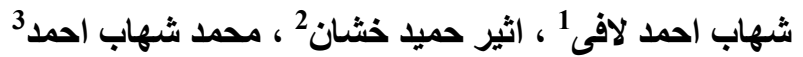

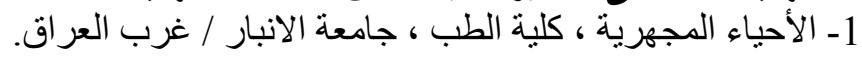

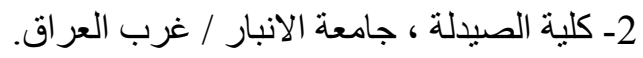

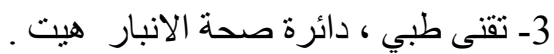

التهاب المجارى البولية هو احد المشـاكل الصحية في المجتمع لمختلف الأعمار وكلى الجنسين وان الجر اثثم

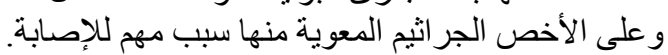

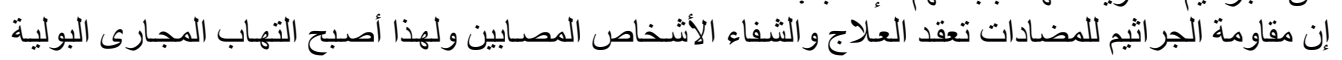

أكثر تعقيدا ويسبب مشاكل للمجتمع.

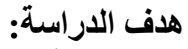

أجريت هذه الدراسة لتسليط الضوء على الجر اثيم المرضية التي تسبب التهاب المجارى البولية في الأثخاص الثاص

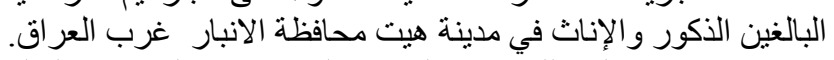
إضافة إلى ذلك هدفت الدر اسة إلى حساسية الجرثومة الغالب عزلهات الها من المرضى لبعض المضادات الجرثومية.

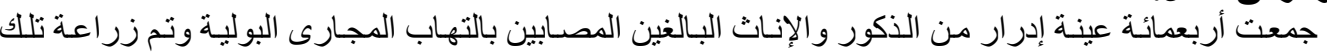

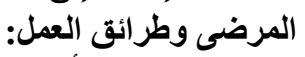

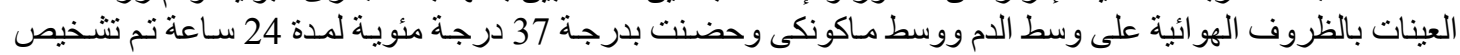

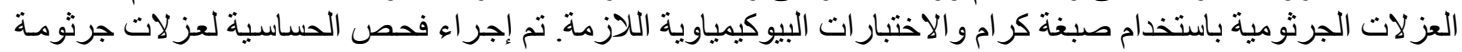

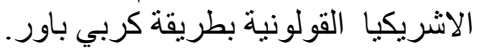

كانت نسبة الإناث المصابات بالتهاب المجارى البولية أكثر منها في الرجال

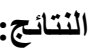

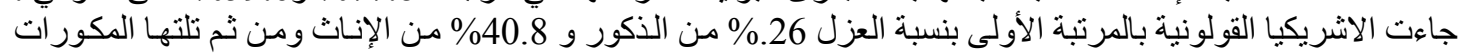

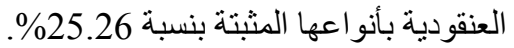

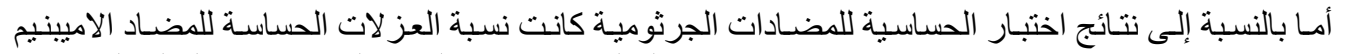

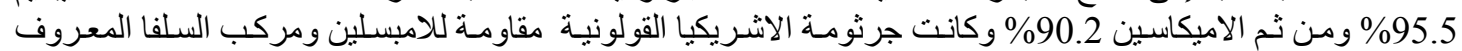

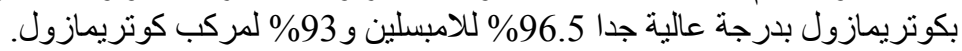
الخاتمة : بكازول

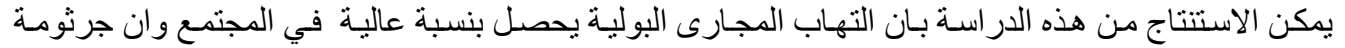

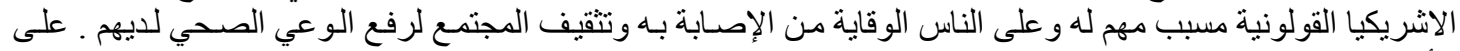

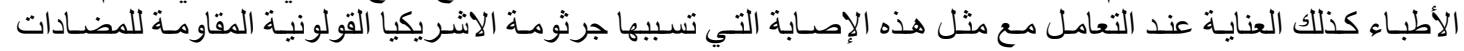

